\title{
The Short Term Effects of Ankle Strengthening Emphasis with Jumping on Strength, Mechanical Properties, and Balance with and without Wearing High Heel in Ankle Instability
}

\author{
YeJi Shin', TaeLim Yoon ${ }^{2}$ \\ 'Department of Physical Therapy, Cheongju ST. Mary's Hospital, Cheongju; ${ }^{2}$ Department of Physical Therapy, College of Health \& medical Science, \\ Cheongju University, Cheongju, Korea
}

Purpose: The purpose of this study was to investigate the short term effects of ASE (ankle strengthening with emphasis on jumping) for 3weeks on strength, mechanical properties, and balance and to compare the balance with and without HH(high-heel) condition.

Methods: ASEJ (a combined exercise of squat, heel raise up, and jumping) were performed for the subjects in 11 female ankle instability young females $(21.7 \pm 2.0$ yrs Cumberland ankle instability score $19 \pm 6.5)$. To investigate the effect of ASEJ, investigator used dynamometer for measuring strength, MyotonPRO for measuring mechanical properties(tone, stiffness, and elasticity of the muscles), I-Balance test for static balance, and Y-balance test for dynamic balance between the condition with and without HH condition. All data were normally distributed and analyzed using the SPSS 22.0 statistical program. Comparing pre- and post-intervention and the condition with and without $\mathrm{HH}$ conditions data were examined using the paired t-test. The level of significance was chosen as 0.05 for all the analyses. Results: 3wks of ASEJ would strengthen leg muscles and increasing muscle tone and stiffness in most muscles however there was decreasing muscle elasticity of gastrocnemious. In addition, the ASE improves the static balance for ankle instability young females and increases the dynamic balance when wearing the heels especially.

Conclusion: the ASE could recommend to improve the strength and balance for ankle instability young females. Also, measuring the balance with $\mathrm{HH}$ conditions well represents the risk of ankle damage in female.

Keywords: Ankle instability, Balance, Jumping exercise

\section{INTRODUCTION}

The chronic ankle instability is largely divided into mechanical and functional. First, it is defined as structural instability, In other words, ligament relaxation. ${ }^{1}$ Second, functional ankle instability is defined as debilitating condition incorporating recurrent sprains, persistent pain and repeated instances of giving way. ${ }^{2}$ The condition is multifactorial with contributions from static alignment, muscle weakness, poor proprioception, and ligamentous injury. This is a clinically important problem because the ankle is one of the most commonly injured joints in the body with more body weight per unit area than the other joints of the body. ${ }^{3}$ This disorder is mainly seen in women. And, 10 to $30 \%$ of people with ankle instability are re-injured or symptoms last for at least 6 months. ${ }^{4}$ In addition, people

Received Jun 20, 2019 Revised Jul 12, 2019

Accepted Jul 25, 2019

Corresponding author TaeLim Yoon

E-mail free0829@gmail.com have ankle instability and a recurrence rate of around 70 to $80 \%$ after ankle injury. ${ }^{5}$ Therefore, it is considered that training to prevent re-injury of the ankle is most important during rehabilitation of the ankle.

In order to recover ankle instability, therapeutic intervention such as ankle strength training, ${ }^{6}$ proprioceptive training, ${ }^{7}$ balance training, ${ }^{8}$ imagination exercise, isokinetic exercise, and taping therapy for supporting ankle structure is being performed and continuous research on effective intervention method of ankle instability. Most of the above exercise protocols include a plyometric exercise element including a jump motion in all programs except a simple muscle strength improving program. ${ }^{9} \mathrm{Ply}$ ometric of jump has been used to improve neuromuscular control and dynamic stability, reduce the incidence of serious knee injuries, and increase the functional joint stability of the lower limb to reduce the risk of

Copylight (C)2019 The Korean Society of Physical Therapy

This is an Open Access article distribute under the terms of the Creative Commons Attribution Non-commercial License (Http:// creativecommons.org/license/by-nc/4.o.) which permits unrestricted non-commercial use, distribution, and reproduction in any medium, provided the original work is properly cited. 
injury. ${ }^{10}$ Because plyometric exercises (jumping) result in higher muscle tension than traditional training programs, they are widely recommended to improve strength, balance, and walking speed.

The effect of jumping exercise has been reported to have positive effects on physical function for individual with ankle instability. A previous study reported an increase in balance in most directions when the Star Excursion Balance Test (SEBT) was performed after jumping exercises in young females with ankle stability due to ankle sprain. ${ }^{11}$ Another study reported that jumping exercise group in elderly people showed significant higher performance on timed up and go (TUG), Berg balance scale (BBS), gait speed, lower extremity strength, and quality of life than control group. ${ }^{12}$ Consequently, ankle strengthening with emphasis on jumping (ASEJ) should be widely applied ankle instability young females.

The use of HH (high-heel) conditions have adverse effects on leg joints, especially ankle joint movements, in both static and dynamic balance. ${ }^{13}$ As many young women want to look like taller and more fashionable, They prefer wearing $\mathrm{HH}$ conditions during their daily lives. Therefore, joints are often damaged when wearing $\mathrm{HH}$ conditions14. The use of $\mathrm{HH}$ conditions makes the distribution of weight pressure on the foot and ankle unbalanced, increases the balance threshold, and changes the posture and balance mechanism during walking. ${ }^{15} \mathrm{HH}$ conditions can negatively affect walking and balance functions, such as increasing plantar flexion and centering the weight distribution in front of the foot, changing body alignment, which is prominent in the ankle joint. ${ }^{16}$ The center of gravity in the upper body shifts to the front side and the lower body moves backward when standing with the $\mathrm{HH}$ conditioned. ${ }^{17}$

Many previous studies with ankle instability only performed in the barefoot during the evaluation although most ankle injuries occur in wearing $\mathrm{HH}$ conditions. The wearing in heel height would affects the reaction force, the impact force, muscle activation, and balance function. ${ }^{18}$ This report imply that the balance function with wearing $\mathrm{HH}$ conditions would not be the same as barefoot. Therefore, rather than measuring the balance with barefoot on a flat surface, the balance needs to be measured in a functional state as the condition with wearing $\mathrm{HH}$ conditions. However, there have been no studies on comparing the effect of jumping exercise on the balance with condition of wearing $\mathrm{HH}$ conditions and barefoot on a flat surface.

The purpose of this study was 1) to investigate the effect of ankle strengthening emphasis with jumping for 3 wks on strength, mechanical properties, and balance and 2) to compare the balance with and without $\mathrm{HH}$ condition in ankle instability young females.

\section{METHODS}

\section{Subjects}

G-power analysis software was used with $\mathrm{G}^{\star}$ power software ver. 3.1.2 (Franz Faul, University of Kiel, Kiel, Germany). The necessary sample size of 8 subjects was calculated with 0.80 power, 0.05 a level, and 1.48 effect size from data obtained from a pilot study. The subjects of this study were 11 ankle instability adults (in Table 1).

The study inclusion criteria subjects were those who felt unstable or giving way to the ankle, those who could perform training or activities of daily living without pain, those who were not currently participating in rehabilitation programs, and those without edema and instability ankle was rated Cumberland ankle instability tool (CAIT) score less than 24 points. Cumberland ankle instability instrument (ICC2, 1.96) was used to identify ankle instability. It consists of 9 questions, 5 of which are from 3 to 0,2 are from 4 to 0,1 is from 5 to 0 , and 1 is from 2 to 0 Respectively. A total score of less than 24 points was defined as an unstable ankle. The higher the score, the closer to normal, and the lower the score, the less stable?

Participants were excluded from the study if they had previous fractures of the legs, past surgery on the lower extremities, ankle sprain within the past $3 \mathrm{wks}$, palpable pain or exudation of the ankle at the time of examination, neurological, visual or neurological disorders, prostate deficiency, orthopedic problems, or other serious condition may affect performance, or interfere with balance of the participant. ${ }^{19}$ All participants provided verbal and written information about the study and signed a consent form. This study was approved by Cheongju University's Research and Ethics Committee(approval number: 1041107-201802-HE-016-01).

\section{Instruments}

\section{1) I Balance $S$}

Static balance was evaluated using an automatic balance calibration system (I Balance S; CyberMedic Co., Iksan, Korea). The system uses four load cells with force plates to measure the center of gravity (COG) shake

Table 1. The general characteristic of subjects

\begin{tabular}{lc}
\hline Characteristics & Participants $(n=11)$ \\
\hline Age $($ year $)$ & $21.7 \pm 2.0$ \\
Height $(\mathrm{cm})$ & $161 \pm 9.0$ \\
Weight $(\mathrm{kg})$ & $54.8 \pm 11.5$ \\
BMI $\left(\mathrm{kg} / \mathrm{m}^{2}\right)$ & $21.1 \pm 2.2$ \\
CAIT $($ score $)$ & $19 \pm 6.5$ \\
\hline
\end{tabular}

Values are presented as mean \pm standard deviation, BMI: body mass index, CAIT: cumberland ankle instability tool. 
speed of the COG and the total swing distance of the COG. The participant stood on the plate with both feet separated comfortably and both hands positioned on the chest. Balance assessment with eyes were opened and closed on hard surfaces and unstable (sponge) surfaces were measured. In order to, reduce the error of the measurement value of the malfunction of the test equipment, the evaluation was repeated 3 times. And the averaged data were used for analysis.

\section{2) Y-balance}

The Y-balance test is a developed version of the standardized the modified Star Excursion Balance Test (mSEBT) and is a simple and reliable test to evaluate the dynamic balance. ${ }^{20,21}$ The subject maintained a single-leg stance with hands on the pelvis while pushing the reach indicator block with the contralateral leg as far as possible along the three directions and checking participant's balance ability. Y-balance tests are three-way tests anterior, posterolmedial, and posterolateral directions while standing on the other foot on a central footplate. ${ }^{22}$ The interrater test-retest reliability of the reported Y-balance test was $0.80-0.85 .{ }^{21}$ Other studies have reported that the range of intrarater reliability is $0.85-0.91$ and interrater reliability is $0.99-1.00 .^{20}$ To compensate for the difference in leg length, a standardization formula was used. The evaluation was repeated 3 times. And the averaged data were used for analysis.

$\square$ Normalization $=$ Excursion distance $/$ Leg length $\mathrm{x} 100$

\section{3) Dynamometer}

Hand held dynamometer (Power Track II commander, J-Tech Medical, Salt Lake City, UT) measured muscle strength in low extremity. The maximal isometric strengths of the hip flexor, hip extensor, knee flexor, knee extensor, dorsi flexor and plantar flexor was measured using Kendall's method. ${ }^{23}$ The dynamometer was zeroed prior to testing. Participants had two practice trials and three test trials. The peak value $(\mathrm{N}=\mathrm{Newton})$ from the three test trials was recorded and averaged for data analyses. The same examiner performed the low extremity for all participants. ${ }^{24}$

\section{4) MyotonPRO}

MyotonPRO (MyotonAS, Estonia and MyotonLtd, London) measured the muscle tone, stiffness and elasticity of the hip flexor, hip extensor, knee flexor, knee extensor, dorsi flexor and plantar flexor. The MyotonPRO device was placed on the skin perpendicular over the muscle belly. In the present study, Oscillation Frequency $[\mathrm{Hz}]$ indicates the tone (that is, intrinsic tension) of a muscle in its passive or resting state without any vol- untary contraction (Electromyography base level). Hypertonia and respectively increased intramuscular pressure causes reduced blood supply, which brings on worse muscle recovery and quicker muscle fatigue. Oscillation Frequency in contracted state indicates the tension of a muscle. Stiffness $[\mathrm{N} / \mathrm{m}]$ is the biomechanical property of a muscle that characterizes the resistance to a contraction or to an external force that deforms its initial shape. Greater effort is required from the agonist muscle to extend the antagonist muscle with high stiffness, which leads to inefficient economy of movement. Logarithmic Decrement of a muscle's natural oscillation indicates the muscle's elasticity.

Elasticity is the biomechanical property of a muscle that characterises the ability to recover its initial shape after a contraction or removal of an external force. Elasticity is inversely proportional to the decrement. If the muscle dissipates less mechanical energy then it is more elastic. If the muscle is more elastic then it is more economic and efficient in function. ${ }^{25,26}$

The device is applied under constant preload $(0.18 \mathrm{~N})$, to pre-compress subcutaneous tissues, the impulse of 0.4 Newtons is automatically increased to instantly apply an impulse of $0.58 \mathrm{~N}$ to the skin at 15 millisecond intervals. Biomechanical indicators are then identified by measuring skin surface oscillations induced by MyotonPRO, ${ }^{27}$

\section{5) ASEJ}

ASEJ was a combined exercise of squat, heel raise up, and jumping. The squat is the action of standing and standing until the thigh is level with the knee and the most basic lower body exercise. ${ }^{28,29}$ The squat causes ankle, knee and hip movements at the same time. ${ }^{30}$ Heel raise up exercise are common exercises included in resistance training programs for increasing the size, strength, and power of the gastrocnemius and soleus muscles 31 . When jumping exercise, the subjects jumped the unstable legs in the vertical direction. Only jumps of more than $2 \mathrm{~cm}$ were recognized on the ground. If the jump height is less than $2 \mathrm{~cm}$, the supervisor does not count. The jumping frequency was 3 times in 10 self-paced jumps and the intensity of jumping was self-paced. The subjects were constantly encouraged to maintain a high level of effort. To prevent falls, the subjects performed exercises with supervision by a physical therapist. All exercises were performed while wearing gymnastic shoes. ${ }^{12}$

\section{6) Experimental procedure}

Before data collection, each subject was exercises after familiarization period for five minutes. The balance ability, mechanical properties, and strength in low extremity were collected for the pre-test. Pre-test was con- 
ducted on the condition of $\mathrm{HH}$ conditions before the intervention and balance test on the bare feet. After the intervention, we also tested the balance ability on the bare feet and wearing $\mathrm{HH}$ conditions. After the pretest, ASEJ program for 40 minutes a day, two times a week for 3 wks under the guidance of a physical therapist. The participants did not receive any other interventions associated with the ankle while this research was being conducted. The post-test was carried out with the same protocol as the pre-test after 3 wks. Each subject included a warm-up 5 min, ASEJ $30 \mathrm{~min}$, and cooling down $5 \mathrm{~min}$. The total exercising time was 40 minutes in each subject. The groups performed the program activity under the supervision of physical therapist. The design of this study is pre-post test design as shown in Figure 1.

\section{Statistical analysis}

Data were analyzed using the SPSS 22.0 statistical program (SPSS, Inc., an IBM Company, Chicago, IL, USA). For the normality test, KolmogorovSmirnov was performed confirming that the data are normally distributed. Pre- and post-intervention data, pre-intervention without-with $\mathrm{HH}$ conditions data and post-intervention without-with $\mathrm{HH}$ conditions data were examined using the paired t-test. The level of significance was chosen as $5 \%$ for all the analyses.

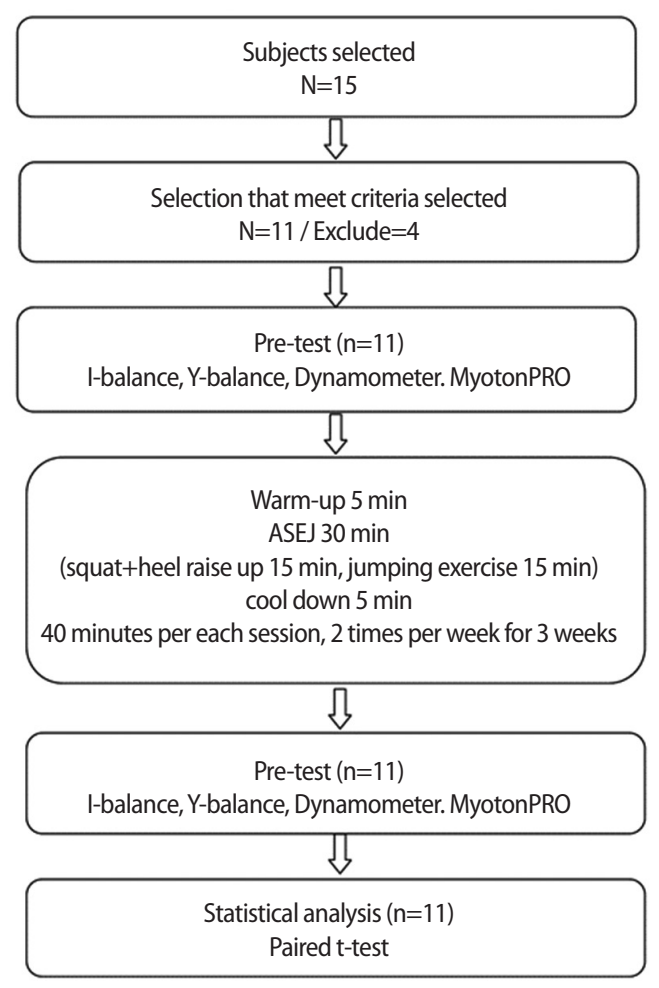

Figure 1. Flow chart of the study

\section{RESULTS}

The COG sway velocity was compared in four conditions (with and without $\mathrm{HH}$ condition/pre and post intervention). The differences of COG sway velocity in each four conditions were mostly significant except pre-post intervention with HH condition in Firm-EC (eyes closed) and pre-post intervention without $\mathrm{HH}$ condition in Unstable -EC ( $\mathrm{p}<0.05)$ (Table 2).

All directions in Y-balance with $\mathrm{HH}$ conditions were significantly improved when ASEJ was performed $(\mathrm{p}<0.05)$. There was a statistically significant difference in posteromedial directions between pre and post exercise condition without $\mathrm{HH}$ conditions. There is only a statistically significant difference in posterolateral direction between with and without $\mathrm{HH}$ conditions before and after intervention in Table 3 .

The results of comparing the muscle strength of the lower extremities before and after jumping exercise are shown in Table 4 . There was a statistically significant difference in all muscles before and after ASEJ $(\mathrm{p}<0.05)$.

Mechanical properties in most muscles respectively showed significant differences after jumping exercise training $(\mathrm{p}<0.05)$ (Table 5).

\section{DISCUSSION}

The purpose of the current study was 1) to investigate the effect of jumping exercise for 3 wks on strength, mechanical properties, and balance and 2) to compare the balance with and without $\mathrm{HH}$ conditions in ankle instability young females. As a result of this study, there were some significant differences in strength, mechanical properties, and balance after 3

Table 2. Comparison of COG velocity (I-balance S between with and without $\mathrm{HH}$ conditions before and after intervention).

\begin{tabular}{llll}
\hline & & $\begin{array}{c}\text { With HH } \\
\text { conditions }\end{array}$ & $\begin{array}{c}\text { Without HH } \\
\text { conditions }\end{array}$ \\
\hline Firm-EO (\%) & Pre-test & $0.04 \pm 0.01$ & $0.03 \pm 0.00^{+}$ \\
& Post-test & $0.03 \pm 0.00^{*}$ & $0.26 \pm 0.00^{++}$ \\
Firm-EC (\%) & Pre-test & $0.23 \pm 0.06$ & $0.18 \pm 0.03^{+}$ \\
& Post-test & $0.20 \pm 0.03$ & $0.14 \pm 0.02^{++}$ \\
Unstable-EO $(\% / \mathrm{s})$ & Pre-test & $0.22 \pm 0.04$ & $0.38 \pm 0.07^{+}$ \\
& Post-test & $0.19 \pm 0.04^{*}$ & $0.31 \pm 0.10^{++}$ \\
Unstable -EC $(\% / \mathrm{s})$ & Pre-test & $0.43 \pm 0.07$ & $0.19 \pm 0.03^{+}$ \\
& Post-test & $0.35 \pm 0.08^{*}$ & $0.17 \pm 0.03^{+}$ \\
\hline
\end{tabular}

Values are presented as mean \pm standard deviation, *Significant difference between pre- and post-test with $\mathrm{HH}$ conditions $(p<0.05)$. Significant difference between pre- and post-test without HH conditions $(p<0.05)$. ${ }^{\ddagger}$ Significant difference between the conditions with and without $\mathrm{HH}$ conditions in pre-test $(p<0.05)$. "Significant difference between the conditions with and without $\mathrm{HH}$ conditions in post-test $(p<0.05)$. COG: center of gravity, EC: eyes closed, EO: eyes open, $\mathrm{HH}$ : high-heel. 
wks of ASEJ with wearing $\mathrm{HH}$ conditions and barefoot. Also, there were significantly different result in measured balance between the condition of with and without $\mathrm{HH}$ conditions.

In our study, The changes of COG sway velocity in each four conditions were improved in the condition with $\mathrm{HH}$ condition and without $\mathrm{HH}$ condition after 3 wks of ASEJ although there was no significant difference in pre-post intervention with $\mathrm{HH}$ condition in Firm-EC and pre-post intervention without $\mathrm{HH}$ condition in Unstable -EC ( $\mathrm{p}$ values $=0.51$ and 0.59 ). In a previous study, the author claimed that jumping exercise resulted in significant improvement sway distance due to increasing of muscle strength and balance ability with seniors. ${ }^{12}$ Therefore, the ASEJ could recommend to improve the balance for ankle instability young females regardless of whether wearing or not wearing $\mathrm{HH}$ conditions.

The changes of COG showed significant difference between the conditions wearing $\mathrm{HH}$ conditions and not wearing $\mathrm{HH}$ conditions regardless

Table 3. Comparison of direction (Y-balance between with and without $\mathrm{HH}$ conditions before and after intervention)

\begin{tabular}{llll}
\hline Reach direction & & $\begin{array}{c}\text { With HH } \\
\text { conditions }\end{array}$ & $\begin{array}{c}\text { Without HH } \\
\text { conditions }\end{array}$ \\
\hline Anterior $(\mathrm{cm})$ & Pre-test & $37.19 \pm 7.18$ & $43.39 \pm 7.12$ \\
& Post-test & $43.33 \pm 5.25^{*}$ & $46.90 \pm 5.04$ \\
Posteromedial $(\mathrm{cm})$ & Pre-test & $51.38 \pm 6.50$ & $57.06 \pm 8.32$ \\
& Post-test & $59.86 \pm 6.69^{*}$ & $65.66 \pm 5.01^{+}$ \\
Posterolateral $(\mathrm{cm})$ & Pre-test & $47.51 \pm 8.35$ & $56.89 \pm 7.76^{+}$ \\
& Post-test & $53.24 \pm 6.14^{*}$ & $60.48 \pm 6.78^{+}$ \\
\hline
\end{tabular}

Values are presented as mean \pm standard deviation, *Significant difference between pre- and post-test with $\mathrm{HH}$ conditions $(\mathrm{p}<0.05)$. ${ }^{+}$Significant difference between pre- and post-test without $\mathrm{HH}$ conditions $(p<0.05)$. 'Significant difference between the conditions with and without $\mathrm{HH}$ conditions in pre-test $(p<0.05)$. 'Significant difference between the conditions with and without $\mathrm{HH}$ conditions in post-test $(\mathrm{p}<0.05)$. HH: high-heel. of pre and post tests. This imply that the measuring of balance functions are different between the conditions wearing and not wearing $\mathrm{HH}$ conditions. Many previous studies have reported that the heights of the $\mathrm{HH}$ conditions can have a significant impact on the mobility and stability of the foot, which is also related individual's risk for suffering a lateral ankle sprain. ${ }^{36}$ Because balance performance is task specific, it may be more functional to measure the static balance by wearing the $\mathrm{HH}$ conditions rather than measuring the heel balance with bare foot. ${ }^{37}$ Also, the less changes of COG were statistically significant in the condition with $\mathrm{HH}$ condition in Firm-EO than Firm-EC conditions, however the changes of COG were statistically significant in the condition without $\mathrm{HH}$ condition in Firm-EC than Firm-EO conditions regardless of pre and post tests. This interesting result is probably due the differences in dependence on visual compensation when wearing or not wearing HH conditions. Vision is the most vital sensory system and can compensate for a lack or non-reliability of equilibrium and proprioceptive sense from ankle. When wearing $\mathrm{HH}$ conditions, our subjects might use their vision to replace the reduced sense of inherent acceptability of their ankles and become difficult to balance in Firm-EC condition. As a result, when measuring balance in wom-

Table 4. Comparison of muscle strength in low extremity

\begin{tabular}{lccc}
\hline Muscles & Pre-test & Post-test & $p$ \\
\hline Hip flexor $(\mathrm{kg})$ & $23.83 \pm 3.99$ & $32.00 \pm 5.05$ & $0.01^{*}$ \\
Hip extensor $(\mathrm{kg})$ & $26.30 \pm 5.40$ & $36.91 \pm 6.27$ & $0.01^{*}$ \\
Knee flexor $(\mathrm{kg})$ & $19.51 \pm 3.38$ & $26.25 \pm 5.21$ & $0.01^{*}$ \\
Knee extensor $(\mathrm{kg})$ & $29.23 \pm 6.24$ & $36.74 \pm 4.58$ & $0.01^{*}$ \\
Dorsi flexor $(\mathrm{kg})$ & $22.08 \pm 3.87$ & $27.50 \pm 3.44$ & $0.01^{*}$ \\
Plantar flexor $(\mathrm{kg})$ & $27.65 \pm 3.92$ & $37.65 \pm 3.92$ & $0.01^{*}$ \\
\hline
\end{tabular}

Values are presented as mean \pm standard deviation, *Significant difference between pre-and post-test $(p<0.05)$.

Table 5. Comparison of mechanical properties (Muscle tone, elasticity and stiffness in low extremity)

\begin{tabular}{|c|c|c|c|c|}
\hline Muscles & Muscles & Pre-test & Post-test & $\mathrm{p}$ \\
\hline \multirow[t]{3}{*}{ Quadriceps femoris } & Tone $(\mathrm{Hz})$ & $12.96 \pm 1.06$ & $14.70 \pm 1.03$ & $0.01^{*}$ \\
\hline & Elasticity (D Log) & $1.04 \pm 0.25$ & $1.27 \pm 0.12$ & $0.01^{*}$ \\
\hline & Stiffness (N/m) & $201.55 \pm 37.35$ & $251.73 \pm 23.90$ & $0.01^{*}$ \\
\hline \multirow[t]{3}{*}{ Hamstring } & Tone $(\mathrm{Hz})$ & $14.17 \pm 0.65$ & $14.60 \pm 1.41$ & 0.42 \\
\hline & Elasticity (D Log) & $1.10 \pm 0.10$ & $1.17 \pm 0.12$ & 0.13 \\
\hline & Stiffness (N/m) & $225.82 \pm 27.033$ & $231.82 \pm 33.56$ & 0.60 \\
\hline \multirow[t]{3}{*}{ Gastrocnemius } & Tone $(\mathrm{Hz})$ & $14.99 \pm 0.87$ & $24.32 \pm 1.06$ & $0.01^{*}$ \\
\hline & Elasticity (D Log) & $1.51 \pm 0.18$ & $1.12 \pm 0.22$ & $0.01^{*}$ \\
\hline & Stiffness (N/m) & $237.09 \pm 20.87$ & $508.00 \pm 53.91$ & $0.01^{*}$ \\
\hline \multirow[t]{3}{*}{ Tibialis anterior } & Tone $(\mathrm{Hz})$ & $22.28 \pm 2.37$ & $15.74 \pm 1.51$ & $0.01^{*}$ \\
\hline & Elasticity (D Log) & $1.15 \pm 0.26$ & $1.52 \pm 0.25$ & $0.01^{*}$ \\
\hline & Stiffness (N/m) & $427.27 \pm 52.33$ & $258.73 \pm 36.42$ & $0.01^{*}$ \\
\hline
\end{tabular}

Values are presented as mean \pm standard deviation, * Significant difference between pre- and post-test ( $p<0.05)$, D Log: logarithmic. 
en with ankle instability, the result of the balance varies depending on whether wearing or not wearing the $\mathrm{HH}$ conditions, so it is better to measure the balance with the height of the heels that each person uses most. This is an improvement of the static balance ability by strengthening the leg strength and affecting the proprioception enhancement through the intervention of this study in the unstable support which is relatively difficult to maintain the static balance.

In Y-balance test, there the condition with $\mathrm{HH}$ condition showed significantly improved in all directions while there was only a significant difference in posteromedial directions in not wearing $\mathrm{HH}$ condition after $3 \mathrm{wks}$ of ASEJ. Although there have been few studies examining the effect of jumping on dynamic balance, A previous study claimed that jumping exercises in trampoline for students with ankle instability presented similar result with our result in posteromedial (about 15\% increasing) and posterolateral (about 14\% increasing) directions. However, the study reported no significant differences in anterior direction (about 9\%). ${ }^{11}$ Other previous study, analyzed the relationship between muscle strength and dynamic balance for women, reported that the hip extensor muscle showed an anterior dynamic balance, hip joint extensor, hip joint adductor, and knee flexor muscle the strengths of posteromedial and hip joint extensors and knee flexors were positively correlated with posterolateral. ${ }^{38}$ Despite the little disagreement of the results between researches, due to differences in research design and interventions, the jumping exercise lead to an increase in the dynamic balance in the functional state of wearing the heels particularly.

Also, there is a statistically significant difference in posterolateral direction between the wearing with and without $\mathrm{HH}$ conditions before and after intervention. In our study, posterolateral direction is the only group with significant difference between dynamic balance items, and required to be larger control than other anterior direction and posteromedial direction. A previous study reported that the posteromedial component of the Star Excursion Balance Test is highly representative of the balance performance of chronic ankle instability. ${ }^{39}$ Therefore, the condition of wearing $\mathrm{HH}$ conditions may increases the instability of the ankle than barefoot and result in significant difference in posterolateral direction between the wearing with and without $\mathrm{HH}$ conditions in our study.

3 wks ASEJ significantly increase (hip flexor 34.3\%, hip extensor 40.3\%, knee flexor 34.5\%, knee extensor 25.7\%, dorsi flexor 24.5\%, Plantar flexor $36.2 \%)$ the strength in all muscles. This result corresponds with a previous study reported that all muscle strength showed a significant increase (hip flexor $36.8 \%$, hip extensor 48.5, knee flexor $25.9 \%$, knee extensor $36.7 \%$, dorsi flexor $42.7 \%$, Plantar flexor 71.4\%) after the 4 wks jumping exercise in senior individuals. ${ }^{12}$ Also the other study reported that jumping exercise in young females with ankle instability has been reported increasing of strength in tibialis anterior, gastrocnemius muscles. ${ }^{32}$ Also, jumping exercises are the most effective way to improve functional activity by increasing of strength. ${ }^{33}$ Consequently, 3 wks of ASEJ would strengthen leg muscles in ankle instability young females effectively.

Mechanical properties were significantly changed in most of the muscles. Muscle tone and stiffness in all muscle except tibialis anterior were mostly increased after 3 wks of ASEJ. Although there was no previous study that examined the change of mechanical properties of lower extremity muscle during ASEJ, there are some previous studies in studying the effect of plyometric training which is mostly composed with jumping activities. An increase in muscle tone and stiffness at higher levels of torque was found in jump performances (between 7.4 and 27.7\% according to the jump type) after the plyometric training. ${ }^{34}$ Other studies have also found increases between 8.2 and 63.4\% (i.e., depending on the stiffness measurement methods used) in global muscle tone and stiffness. ${ }^{10}$ The author insisted that plyometric training led to specific adaptations within muscle tone and stiffness of muscles.

Also, after 3 wks ASEJ, there was an increase in muscle elasticity in GCM muscle, but in all other muscles, the muscle elasticity was decreased. Elasticity is the ability to recover its initial shape after a contraction or removal of an external force. ${ }^{25,26,35}$ Theses increasing of muscle elasticity in GCM could increase both the efficiency of the energy storage- recoil process and muscular tension transmission leading to an increase in jump performances. ${ }^{34}$ On the other hand, our study showed that the muscle elasticity in other muscles were significantly reduced. The difference in muscle elasticity between these muscles seems to be related to the movement that occurs during exercise. In particular, the jumping and heel raise up exercise consist of concentric and eccentric contraction in GCM. Consequently, the 3 wks ASEJ has the effect of increasing muscle tone and stiffness as well as increasing muscle elasticity of GCM.

This study has several limitations. First, our sample was relatively small. In some of the results, there was no statistical significance due to small sample sizes, This represents a lack of statistical power. Secondly, only young women were included in our study. This indicating that the findings cannot be generalized to the entire population. Third, the effect of ASEJ in a single group with ankle instability without control was studied. Lastly, this study only focused on changes in balance, muscle tone and muscle strength after performance of ASEJ. In future studies, measurement of gait should be performed after performance of ASEJ. Also, future studies 
should include a higher number of subjects from various age groups.

\section{CONCLUSIONS}

We recommend using the ASEJ which emphasizes jumping rather than simple muscle strength improving program for strengthening and improving balance in individuals with ankle instability. Also, it is better to measure the balance with the height of the heels that each person uses most due to the significantly different result in measured balance between the condition of with and without $\mathrm{HH}$ conditions.

\section{References}

1. Choi HS, Shin WS, Shim JK et al. The relationship between functional movement screen and ankle dysfunctions with chronic ankle instability. J Kor Soc Phys Ther. 2014;26(6):459-63.

2. Freeman M. Instability of the foot after injuries to the lateral ligament of the ankle. J Bone Joint Surg Br. 1965;47(4):669-77.

3. Hertel J. Sensorimotor deficits with ankle sprains and chronic ankle instability. Clinics in Sports Medicine. 2008;27(3):353-70.

4. Holmes A, Delahunt E. Treatment of common deficits associated with chronic ankle instability. Sports Med. 2009;39(3):207-24.

5. Hiller CE, Refshauge KM, Bundy AC et al. The cumberland ankle instability tool: a report of validity and reliability testing. Arch Phys Med Rehabil. 2006;87(9):1235-41.

6. Smith BI, Docherty CL, Simon J et al. Ankle strength and force sense after a progressive, 6-week strength training program in people with functional ankle instability. J Athl Train. 2012;47(3):282-8.

7. Kim KJ. The effect of strength and proprioception combined training on functional ankle instability. Dongshin University. Dissertation of Master' s Degree. 2012.

8. Kim JH, Uhm YH. Effect of ankle stabilization training using biofeedback on balance ability and lower limb muscle activity in football players with functional ankle instability. J Kor Phys Ther. 2016;28(3):189-94.

9. Kotzamanidis C. Effect of plyometric training on running performance and vertical jumping in prepubertal boys. J Strength Cond Res. 2006; 20(2):441-5.

10. Kubo K, Morimoto M, Komuro T et al. Effects of plyometric and weight training on muscle-tendon complex and jump performance. Med Sci Sports Exerc. 2007;39(10):1801-10.

11. Cha SH, Kim JS. The effects of balance exercises on functional ankle stability with ankle sprained patients. Health Sports Med. 2009;11(2):7383.

12. Park JN, Cho KH, Lee WH. Effect of jumping exercise on muscle strength and balance of elderly people: a randomized controlled trial. J Phys Ther Sci. 2012;24(12):1345-8.

13. Lee KH, Shieh JC, Matteliano A et al. Electromyographic changes of leg muscles with heel lifts in women: therapeutic implications. Arch Phys Med Rehabil. 1990;71(1):31-3.

14. Franklin ME, Chenier TC, Brauninger L et al. Effect of positive heel in- clination on posture. J Orthop Sports Phys Ther. 1995;21(2):94-9.

15. Oh DW. Influences of shoe heel height on isometric shoulder abductor strength and EMG activities of selected shoulder muscles. J Korean Soc Phys Med. 2015;10(2):9-16.

16. Snow RE, Williams KR, Holmes GB. The effects of wearing high heeled shoes on pedal pressure in women. Foot Ankle. 1992;13(2):85-92.

17. Snow RE, Williams KR. High heeled shoes: their effect on center of mass position, posture, three-dimensional kinematics, rearfoot motion, and ground reaction forces. Arch Phys Med Rehabil. 1994;75(5):568-76.

18. Wang YT, Pascoe DD, Kim CK et al. Force patterns of heel strike and toe off on different heel heights in normal walking. Foot Ankle Int. 2001; 22(6):486-92.

19. Sawkins K, Refshauge K, Kilbreath S et al. The placebo effect of ankle taping on ankle instability. Med Sci Sports Exerc. 2007;39(5):781-7.

20. Plisky PJ, Gorman PP, Butler RJ et al. The Reliability of an instrumented device for measuring components of the star excursion balance test. N Am J Sports Phys Ther. 2009;4(2):92-9.

21. Shaffer SW, Teyhen DS, Lorenson CL et al. Y-Balance Test: a reliability study involving multiple raters. Mil Med. 2013;178(11):1264-70.

22. Wilson BR, Robertson KE, Burnham JM et al. The relationship between hip strength and the Y balance test. J Sport Rehabil. 2018;27(5):445-50

23. Kendall FP, McCreary EK. Muscles: testing and function, 3rd edition by plorence peterson kendall. Br J Sports Med. 1984;18(1):25.

24. Gordon AT, Ambegaonkar JP, Caswell SV. Relationships between core strength, hip external rotator muscle strength, and star excursion balance test performance in female lacrosse players. Int J Sports Phys Ther. 2013;8(2):97-104.

25. Fung YC. Biomechanics: mechanical properties of living tissues. Berlin. Springer Science \& Business Media; 2013.

26. Özkaya N, Leger D, Goldsheyder D et al. Fundamentals of Biomechanics: Equilibrium, Motion, and Deformation. Berlin Springer; 2016.

27. Aird L, Samuel D, Stokes M. Quadriceps muscle tone, elasticity and stiffness in older males: reliability and symmetry using the MyotonPRO. Arch Gerontol Geriatr. 2012;55(2):e31-9.

28. Isear JJ, Erickson JC, Worrell TW. EMG analysis of lower extremity muscle recruitment patterns during an unloaded squat. Med Sci Sports Exerc. 1997;29(4):532-9.

29. Shon JW, Lim HW. Comparison of muscle activities of trunk and lower limb during bow and squat exercises. J Kor Phys Ther. 2016;28(2):95100.

30. McGinty G, Irrgang JJ, Pezzullo D. Biomechanical considerations for rehabilitation of the knee. Clin Biomech. 2000;15(3):160-6.

31. Riemann BL, Limbaugh GK, Eitner JD et al. Medial and lateral gastrocnemius activation differences during heel-raise exercise with three different foot positions. J Strength Cond Res. 2011;25(3):634-9.

32. Kim JS. The effects of trampoline exercise on ankle's CAI index, muscle activation, and functional performance. Hanyang University. Dissertation of Master's Degree. 2017.

33. Cakar E, Dincer U, Kiralp MZ et al. Jumping combined exercise programs reduce fall risk and improve balance and life quality of elderly people who live in a long-term care facility. Eur J Phys Rehabil Med. 2010;46(1):59-67.

34. Fouré A, Nordez A, McNair P, Cornu C. Effects of plyometric training on both active and passive parts of the plantarflexors series elastic com- 
ponent stiffness of muscle-tendon complex. Eur J Appl Physiol. 2011; 111(3):539-48.

35. Athanasiou KA, Natoli RM. Introduction to continuum biomechanics. Synthesis lectures on biomedical engineering. 2008;3(1):1-206.

36. Foster A, Blanchette MG, Chou YC et al. The influence of heel height on frontal plane ankle biomechanics: implications for lateral ankle sprains. Foot Ankle Int. 2012;33(1):64-9.
37. Dunsky A, Zeev A, Netz Y. Balance performance is task specific in older adults. BioMed research international. 2017;1-7.

38. Lee DK, Kim GM, Ha SM et al. Correlation of the Y-balance test with lower-limb strength of adult women. J Phys Ther Sci. 2014;26(5):641-3.

39. Hertel J, Braham RA, Hale SA et al. Simplifying the star excursion balance test: analyses of subjects with and without chronic ankle instability. J Orthop Sports Phys Ther. 2006;36(3):131-7. 